\title{
Prevention of acute postoperative pressure rises in glaucoma patients undergoing cataract extraction with posterior chamber lens implant
}

\author{
James West, John Burke, Ian Cunliffe, Simon Longstaff
}

\begin{abstract}
Acute elevations in intraocular pressure (IOP) commonly follow extracapsular cataract extraction and lens implant in glaucoma patients. Thirty six patients with glaucoma undergoing cataract extraction and posterior chamber lens implantation received one of three treatments. Group 1: $500 \mathrm{mg}$ of Diamox Sustets (acetazolamide) 1 hour preoperatively (10 patients); Group 2: peroperative intracameral Miochol (acetylcholine) (11 patients); Group 3: the above treatments combined (15 patients). IOPs were measured at 3,6, 9, and 24 hours postoperatively. The average of the maximum pressure rises above the preoperative level over the 24 hour period was greatest for the group receiving acetazolamide only at $8.9 \mathrm{~mm} \mathrm{Hg}$; for the acetylcholine group the average maximum rise was $6.3 \mathrm{~mm} \mathrm{Hg}$; while the combined treatment group showed a decrease of $0.7 \mathrm{~mm} \mathrm{Hg}$. IOP rises of $>6 \mathrm{~mm} \mathrm{Hg}$ were seen in $7 \%$ of patients (one of 15 ) in the combined treatment group, $45 \%$ (five of 11 ) of the acetylcholine group, and $70 \%$ (seven of 10 ) of the acetazolamide group. IOP rises of $>10$ $\mathrm{mm} \mathrm{Hg}$ were seen in $7 \%$ of the combined treatment group, in $18 \%$ of the acetylcholine only group, and in $\mathbf{5 0 \%}$ of the acetazolamide only group. A pressure rise $>20 \mathrm{~mm} \mathrm{Hg}$ was seen in one patient receiving acetazolamide only and one patient receiving acetylcholine only. The difference between the acetylcholine group and the combined group for rises $>6 \mathrm{~mm}$ Hg was significant using the $\chi^{2}$ test while the acetazolamide group showed a significant difference for rises $>6$ and $10 \mathrm{~mm} \mathrm{Hg}$ compared with the combined group. All acute pressure rises were recorded before or at 9 hours following operation except in the combined treatment patient where the rise occurred at 24 hours. To prevent the acute IOP rises seen following cataract surgery with lens implant in glaucoma patients we recommend combined ocular hypotensive therapy.

(Brf Ophthalmol 1992; 76: 534-537)
\end{abstract}

Acute rises in intraocular pressure (IOP) commonly follow extracapsular cataract extraction with posterior chamber lens implant surgery (ECCE $+\mathrm{IOL}){ }^{1-4}$ figures reported ranging from 10 to $50 \%$. The frequency and degree of such rises appear greater in patients with pre-existing open angle glaucoma, $70 \%$ of such eyes having an IOP rise $>10 \mathrm{~mm} \mathrm{Hg}$ or more in a recent study. ${ }^{5}$ The already damaged glaucomatous disc may suffer further and worsening and loss of central field following acute IOP rises after ECCE or argon laser trabeculoplasty are well documented. ${ }^{6-11}$ The effectiveness of various ocular hypotensive agents, including carbachol, acetylcholine, and several $\beta$ blockers, at reducing the acute IOP rises have been investigated with some encouraging results, ${ }^{3+1213}$ but not in patients with pre-existing glaucoma undergoing ECCE+ IOL. Because of the lack of research in this important therapeutic area we undertook a study to compare the effectiveness of two agents, with different mechanisms of action, at reducing the acute postoperative IOP rises. Acetazolamide (Diamox) which reduces aqueous production and acetylcholine (Miochol) which increases aqueous outflow were used alone or in combination.

\section{Material and methods}

Ethical committee approval was obtained prior to commencement of the study.

\section{PATIENTS}

Any patient with a diagnosis of open angle glaucoma based on an IOP of more than $21 \mathrm{~mm}$ $\mathrm{Hg}$ prior to treatment and pathological cupping of the optic disc with visual field loss, undergoing ECCE + IOL surgery, were included in the study following informed consent. Patients with previous intraocular surgery were excluded. None of the patients had undergone previous laser trabeculoplasty. All patients were on some form of topical ocular hypotensive agent, some receiving more than one agent.

Patients were randomly allocated to one of three treatment groups. Group 1: received Diamox sustet (acetazolamide) $500 \mathrm{mg}$ orally 1 hour preoperatively; Group 2: received intracameral Miochol (1:100 solution of acetylcholine chloride in 3\% mannitol) at the end of the operation to refill the anterior chamber; Group 3: received both treatments. Acetazolamide and acetylcholine were chosen because of their different mechanisms of action, acetazolamide decreasing aqueous production and acetylcholine increasing aqueous outflow; so in theory, when combined one might expect to see a synergistic effect.

A control group of patients with open angle glaucoma undergoing ECCE $+\mathrm{IOL}$ and receiving no treatment to prevent postoperative IOP rises was not included as it was felt unethical to do so considering the previously reported frequency of acute IOP rises in the literature with the consequent risk of such rises for an already compromised optic disc. 
Table 1 Patient groups

\begin{tabular}{llll}
\hline & Diamox & Miochol & Combined \\
\hline No & 10 & 11 & 15 \\
Mean age & 80 & 78 & 80 \\
M:F & $4: 6$ & $3: 8$ & $2: 13$ \\
\hline
\end{tabular}

All IOP measurements were observer blind and made at the slit-lamp by means of a standardised applanation tonometer used for this study only. Preoperative IOPs were taken the day prior to surgery and postoperative readings at $3,6,9$, and 24 hours following surgery.

Surgery was standardised in all cases to the use of local anaesthesia, corneal section, endocapsular technique, four suture 10/0 nylon closure of the section, and Healonid (sodium hyaluronate) aspiration with a coaxial cannula through the closed section at the end of the procedure.

No complications occurred in any of the surgical procedures and all pupils were adequately dilated. Postoperatively, patients received 2 hourly topical steroid drops and a short acting mydriatic twice daily because of the well known increased risk of uveitis in these patients.

\section{Results}

A total of 36 patients were recruited overall and Table 1 shows the number of patients in each group with age and sex distribution.

The disease severity as judged by the type and duration of preoperative topical therapy and the preoperative IOP level was very similar for all groups. Timolol was the most commonly used topical ocular hypotensive followed by pilocarpine. No correlation was noted between preoperative ocular hypotensive therapy or the preoperative IOP level in those patients in whom an acute rise in IOP occurred.

Fibrinous uveitis was noted in a few cases within 3 to 6 hours of surgery, and its presence did not correlate with acute IOP rises.

In our results we looked at the maximum IOP elevation above the preoperative level over the 24 hour study period and the time period of the acute rises. These were compared for the patients in each of the three groups.

The majority of maximum postoperative IOPs were less than the preoperative level for each patient in the combined treatment group, while the opposite was true for the single treatment

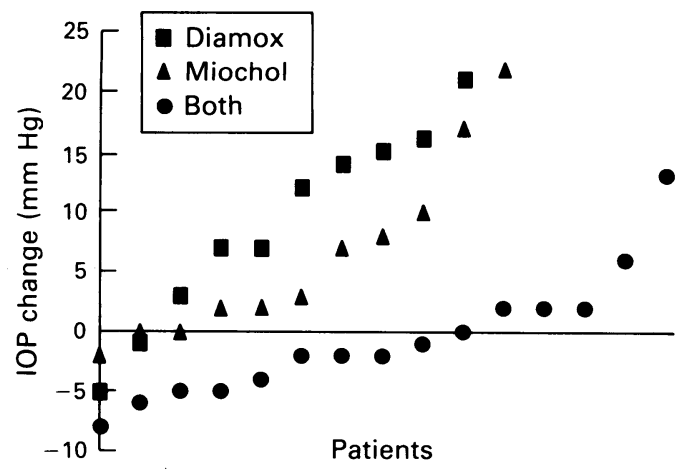

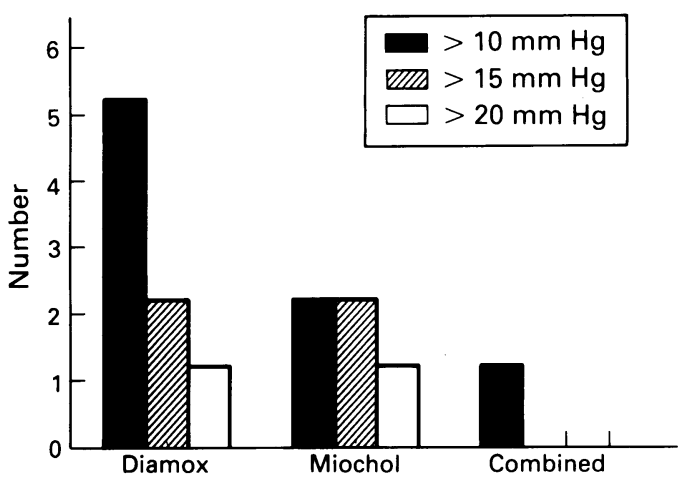

Figure 2 Number of patients in each group showing IOP rises of $>10 \mathrm{~mm} \mathrm{Hg},>15 \mathrm{~mm} \mathrm{Hg}$, and $>20 \mathrm{~mm} \mathrm{Hg}$ over the 24 hour period.

groups. Individual rises or falls for each patient grouped appropriately and in ascending order are shown in Figure 1.

The mean of the maximum IOP rises was +8.9 $\mathrm{mm} \mathrm{Hg}$ for the acetazolamide group, $+6 \cdot 3 \mathrm{~mm}$ $\mathrm{Hg}$ for the acetylcholine group and $-0.7 \mathrm{~mm} \mathrm{Hg}$ for the combined treatment group. The differences between the combined group and the single treatment groups proved significant when compared using Student's $t$ test $(0 \cdot 01>\mathrm{p}$ for acetazolamide $v s$ combined, $0.02>\mathrm{p}$ for acetylcholine $v s$ combined).

Comparing the number and magnitude of IOP rises above the preoperative IOP for each treatment group also showed a marked difference between the combined and the single treatment groups. The difference between the combined group and the acetazolamide group was significant using the $\chi^{2}$ test for rises $>6 \mathrm{~mm} \mathrm{Hg}$ $(0.001>p)$ and for rises $>10 \mathrm{~mm} \mathrm{Hg}(0.01>p)$, while the acetylcholine group showed significance for rises $>6 \mathrm{~mm} \mathrm{Hg}(0.05>\mathrm{p})$. Figure 2 summarises these findings. For each measurement time the number of IOP rises $>10 \mathrm{~mm} \mathrm{Hg}$ above the preoperative level in each group are shown in Figure 3. Both single treatment groups had at least one patient with a rise $>10 \mathrm{~mm} \mathrm{Hg}$ at 3,6 , and 9 hours postoperatively while none of the patients in the combined group showed a rise of this magnitude at these measurement times. A greater number of rises above $10 \mathrm{~mm} \mathrm{Hg}$ occurred at the 3 and 6 hour measurement times compared with the 9 hour measurement time for the acetylcholine group, whereas in the acetazolamide group rises were more numerous at the 6

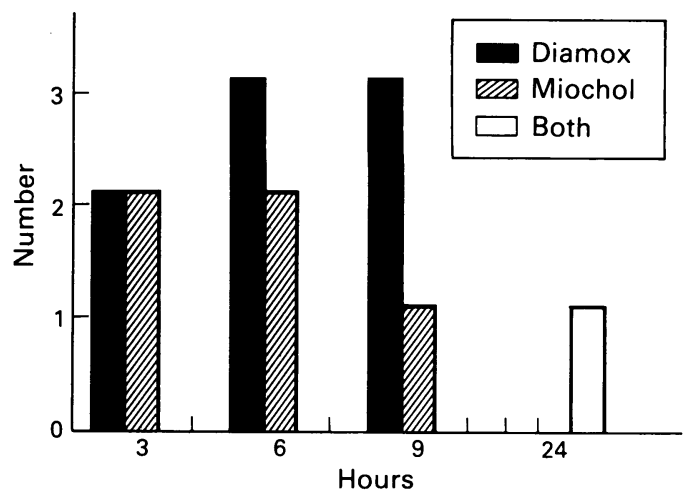

Figure 3 Number of IOP rises $>10 \mathrm{~mm} \mathrm{Hg} \mathrm{recorded} \mathrm{at} \mathrm{each}$ measurement time for each of the treatment groups. 
and 9 hour measurement times. Only one patient at 24 hours postoperatively had a rise $>10 \mathrm{~mm}$ $\mathrm{Hg}$ and this patient was from the combined group.

\section{Discussion}

Early postoperative pressure rises within the first 24 hours in eyes undergoing ECCE + IOL are commonly seen and appear to be maximum at about 6 to 9 hours post surgery. ${ }^{31314}$ These early pressure rises are seen more commonly (up to $70 \%$ in a recent series ${ }^{5}$ ) and are of great magnitude in patients with open angle glaucoma undergoing $\mathrm{ECCE}+\mathrm{IOL}$.

A variety of ocular hypotensive agents has been investigated for their ability to prevent these acute postoperative pressure rises with some encouraging results, ${ }^{34^{12} 13}$ but no investigation has taken place in glaucoma patients undergoing ECCE + IOL.

Savage et $a l^{6}$ described worsening of the visual field following ECCE in $\mathbf{9 . 7 \%}$ of glaucomatous eyes with severe preoperative field loss (split fixation or central field $<10$ degrees). The potential hazard of acute postoperative IOP rises in an already severely damaged eye with vulnerable optic nerve was suggested and is further supported by other reports in the literature. Hayreh' reported 13 cases of anterior ischaemic optic neuropathy following cataract surgery, 11 of which had documented postoperative IOP rises; $\mathrm{Kolker}^{8}$ reported loss of central vision in $2 / 23(8 \cdot 7 \%)$ eyes with advanced glaucoma undergoing cataract surgery (ICCE); Weinreb ${ }^{10}$ and Thomas ${ }^{11}$ have reported marked loss of visual field and central vision in association with a substantial rise in IOP following argon laser trabeculoplasty.

Despite antihypertensive treatment acute IOP rises were seen in our patients. However, the combination of both agents proved significantly better at preventing the rises than either agent alone. It is interesting that acetylcholine appeared to perform better than acetazolamide as one would expect the meshwork reserve to be low in most of these patients. For both single treatment groups the greatest number of rises above $10 \mathrm{~mm}$ $\mathrm{Hg}$ occurred at 6 hours post surgery, and the acute rises above $10 \mathrm{~mm} \mathrm{Hg}$ in acetylcholine treated patients occurred earlier than those in the acetazolamide treated patients. The only rise of more than $10 \mathrm{~mm} \mathrm{Hg}$ in the combined treatment group occurred at 24 hours post surgery and it is possible that this rise is an escape phenomenon as one would expect the effects of both drugs to have passed by this time.

Some cases of early fibrinous uveitis were seen at 3 to 6 hours following surgery. However patients with open angle glaucoma, who have been on long term antiglaucoma medication and who are undergoing cataract surgery, are known to be at high risk of developing severe postoperative uveitis irrespective of iris trauma during surgery, ${ }^{15}$ and none of those patients with an acute postoperative uveitis in this study developed an acute IOP rise.

Another approach to protecting the optic nerve from acute IOP rises is glaucoma triple surgery which has been shown to reduce the frequency and magnitude of early postoperative pressure rises in glaucoma patients. ${ }^{516}$ However the acute IOP rises are not eliminated by this technique. Furthermore, glaucoma triple surgery is associated with a higher postoperative complication rate and a longer period for visual recovery restricting its use in eyes where topical antiglaucoma medication is effective at maintaining IOP control. ${ }^{17-21}$ For the majority of glaucoma patients who have a preoperatively controlled IOP on medical therapy simple ECCE +IOL is the operation of choice as cataract surgery alone is associated with better long term postoperative IOP control. ${ }^{622-24}$ These patients are at significant risk of developing acute postoperative IOP rises which could cause additional irreversible damage to an already compromised optic disc. An effective means of preventing these acute postoperative IOP rises can only benefit glaucoma patients undergoing ECCE+ IOL.

Our findings suggest a combination of preoperative acetazolamide and intracameral acetylcholine, two agents having different and distinct pharmacological effects on aqueous turnover, is the most effective means of preventing such IOP rises.

We thank our colleagues for their help in recruiting patients for our study.

1 Tuberville A, Tomoda T, Nissenkorn I, Wood TO. Post surgical intraocular pressure elevation. Am Intraocul Implant Soc ₹ 1983; 9: 309-12.

2 Gross JG, Meyer DR, Robin AL, Filar AA, Kelley JS Increased intraocular pressure in the immediate postoperative period after extracapsular cataract extraction. Am fOphthalmol 1988; 105: 446-9.

3 Hollands RH, Drance SM, Schulzer M. The effect of acetylcholine on early postoperative intraocular pressure. Am ₹ Ophthalmol 1987; 103: 749-53.

4 Ruiz RS, Wilson CA, Musgrove RH, Prager TC. Management of increased intraocular pressure after cataract extraction. Am 7 Ophthalmol 1987; 103: 487-91.

5 Krupin T, Feitl ME, Bishop KI. Postoperative intraocular pressue rise in open-angle glaucoma patients after cataract or pressue rise in open-angle glaucoma patients after cataract or
combined cataract-filtration surgery. Ophthalmology 1988; combined $579-84$.

6 Savage JA, Thomas JV, Belcher CD III, Simmons RJ. Extracapsular cataract extraction and posterior chamber intraocular lens implantation in glaucomatous eyes. Ophthalmology 1985; 92: 1506-16.

7 Simmons RJ. Contemporary management of coexisting cataract and glaucoma. In: Greve EL, ed. Surgical management of coexisting cataract and glaucoma. Amsterdam: Kugle 1987; 33-9.

8 Kolker AE. Visual prognosis in advanced glaucoma. A comparison of medical and surgical therapy for retention of vision in 101 eyes with advanced glaucoma. Trans Am Ophthalmol Soc 1977; 75: 539-55.

9 Hayreh SS. Anterior ischaemic optic neuropathy. IV. Occurrence after cataract extraction. Arch Ophthalmol 1980; 89: $1410-6$.

10 Weinreb RN, Ruderman J, Juster R, Zweig K. Immediate intraocular pressure response to argon laser trabeculoplasty. Am F Ophthalmol 1983; 95: 279-86.

11 Thomas JV, Simmons RJ, Belcher CD. Argon laser trabeculoplasty in the presurgical glaucoma patient. Ophthalmology 82; 89: 187-97.

12 West DR, Lischwe TD, Thompson VM, Ide CH. Comparative efficacy of the $\beta$ blockers for the prevention of increased intraocular pressure after cataract extraction. Am F Ophthalmol 1988; 106: 168-73.

3 Linn DK, Zimmerman TJ, Nardin GF, Yung R, Berberich S DuBiner $\mathrm{H}$, et al. Effect of intracameral carbachol on intraocular pressure after cataract extraction. Am $\mathcal{F} O$ phthal mol 1989; 107: 133-6.

4 Rich WJ, Radtke ND, Cohan BE. Early ocular hypertension after cataract extraction. Brf Ophthalmol 1974; 58: 725-31. 5 Obstbaum SA. Glaucoma and intraocular lens implantation. f Cataract Refract Surg 1986; 12: 257-61.

6 McGuigan LJB, Gottsch J, Start WJ, Maumenee AE, Quigley HA. Extracapsular cataract extraction and posterio chamber lens implantation in eyes with preexisting glaucoma. Arch Ophthalmol 1986; 104: 1301-8.

17 Longstaff S, Wormald RPL, Mazover A, Hitchings RA Glaucoma triple procedures: efficacy of intraocular pressure control and visual outcome. Ophthalmic Surg 1990; 21:78693.

18 Huber C, Reme $\mathrm{CH}$. Lens implantation combined with 
trabeculectomy. Trans Ophthalmol Soc UK 1985; 104: $574-7$.

19 Jay J. Extracapsular lens extraction and posterior chamber intraocular lens insertion combined with trabeculectomy. $\mathrm{Br}$ f Ophthalmol 1985; 69: 487-90.

20 McCartney DL, Memmen JE, Sark WJ, Quigley HA, Maumenee AE, Gottsch JD, et al. The efficacy and safety of combined trabeculectomy, cataract extraction and intra-

Simmons ST, Litoff D, Nichols DA, Sherwood MB, Spaeth

GL. Extracapsular cataract extraction and posterior GL. Extracapsular cataract extraction and posterior
chamber intraocular lens implantation combined with trabeculectomy in patients and glaucoma. Am F Ophthalmol 1986; 104: 465-70.

22 Greve EL, ed. Extracapsular cataract extraction in primary open angle glaucoma. In: Surgical management of coexisting cataract and glaucoma. Amsterdam: Kugler 1987: 51-57. cataract extraction with posterior chamber lens implantation cats in patients with

24 McMahan LB, Monica ML, Zimmerman TJ. Posterior chamber pseudophakes in glaucoma patients. Ophthalmic
Surg 1986; 17: 146-50. 